\title{
Synthesis and Hydrogen Sorption Properties of Carborane Based Metal-Organic Framework Materials
}

\author{
Omar K. Farha, ${ }^{\dagger}$ Alexander M. Spokoyny,$^{\dagger}$ Karen L. Mulfort, ${ }^{\dagger, \ddagger}$ M. Frederick Hawthorne,$\S$ \\ Chad A. Mirkin,, ${ }^{*}$ and Joseph T. Hupp ${ }^{*, \dagger}$ \\ Department of Chemistry and International Institute for Nanotechnology, Northwestern University, 2145 Sheridan \\ Road, Evanston, Illinois 60208, Chemistry Division, Argonne National Laboratory, Argonne, Illinois 60439, and \\ International Institute of Nano and Molecular Medicine, University of Missouri-Columbia, Missouri 65212
}

Received August 15, 2007; E-mail: j-hupp@northwestern.edu; chadnano@northwestern.edu

Tailorable inorganic coordination polymers, ${ }^{1-7}$ in particular, metal-organic frameworks (MOFs) $)^{2-7}$ comprise an important emerging class of materials. They are noteworthy for their structural and chemical diversity, high internal surface areas, and (often) permanent microporosity. As such, they have attracted great interest for numerous applications including ion exchange, ${ }^{2}$ heterogeneous catalysis, ${ }^{3}$ optoelectronics, ${ }^{4}$ gas separation,,${ }^{5}$ gas sensing, ${ }^{6}$ and gas storage, in particular $\mathrm{H}_{2}$ storage. $^{7}$ Among the factors useful for attaining high gravimetric uptake of $\mathrm{H}_{2}$ are small pores, open metal coordination sites, and low framework mass. Here we report on the synthesis and hydrogen uptake properties of carborane-based MOFs that exploit some or all of these characteristics to achieve surprisingly high $\mathrm{H}_{2}$ uptake. To our knowledge, these are the first metal-organic frameworks to make use of boron-rich components as building blocks. ${ }^{8}$ Carboranes are icosahedral carbon-containing boron clusters possessing several material-favorable properties including rigidity, thermal stability, and chemical stability. Dicarbon carboranes of the form $\mathrm{C}_{2} \mathrm{~B}_{n}-2 \mathrm{H}_{n}(6 \leq n \leq 12)$ may be regarded as three-dimensional delocalized aromatic systems in which surface bonding and core bonding correspond to $\sigma$-bonding and $\pi$-bonding, respectively. ${ }^{9}$ These compounds can be prepared on the kilogram scale and have been used for a variety of applications, including boron neutron capture therapy, molecular delivery devices in biomedicine, and molecular motors. ${ }^{10}$

As a starting point for carborane-based MOFs, we have focused on $\mathrm{Zn}$ (II) coordination of the deprotonated form of 1,12-dihydroxycarbonyl-1,12-dicarba-closo-dodecaborane $\left(p-\mathrm{CDCH}_{2}(\mathbf{1})\right.$; Figure 1A). $p$-CDC ${ }^{2-}$ has approximately the same 2-D footprint as benzene-1,4-dicarboxylate (bdc), the strut defining the archetypal cubic framework compound, MOF-5 $\left[\mathrm{Zn}_{4} \mathrm{O}(\mathrm{bdc})_{3}\right]_{n}$. In comparison with other frameworks, MOF-5 is a good, albeit not spectacular, hydrogen storage material, at least at cryogenic temperatures (1.25 wt $\%$ at $77 \mathrm{~K}$ and $1 \mathrm{~atm}) .{ }^{11}$ We reasoned that by replacing benzene with the three-dimensional carborane (volume approximately that swept out by a rotating phenyl ring) we might obtain a close structural analogue of MOF-5, but with smaller pores and therefore higher heats of adsorption. Such a change could lead to higher hydrogen loading at low temperatures and modest pressures and/ or more persistent loading at higher temperatures. ${ }^{12}$ The solvothermal synthesis instead yielded a more complex MOF of the formula $\left[\mathrm{Zn}_{3}(\mathrm{OH})(p-\mathrm{CDC})_{2.5}(\mathrm{DEF})_{4}\right]_{n}(\mathbf{2})[\mathrm{DEF}=$ diethylformamide $]$ (Figure 1). Compound 2 deviates from MOF-5 because of the sterics imposed by the cage and/or the source of the zinc ion used. ${ }^{13} \mathrm{X}$-ray analysis of a single crystal of $\mathbf{2}$ revealed a structure in which two of the three zinc ions are coordinated to two DEF molecules, each

\footnotetext{
$\dagger$ Northwestern University.

\# Argonne National Laboratory.

$\S$ University of Missouri-Columbia
}

A

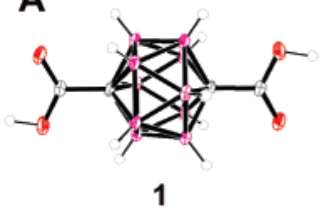

C

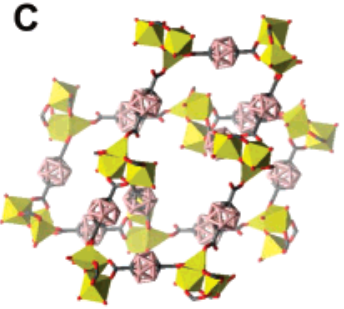

2
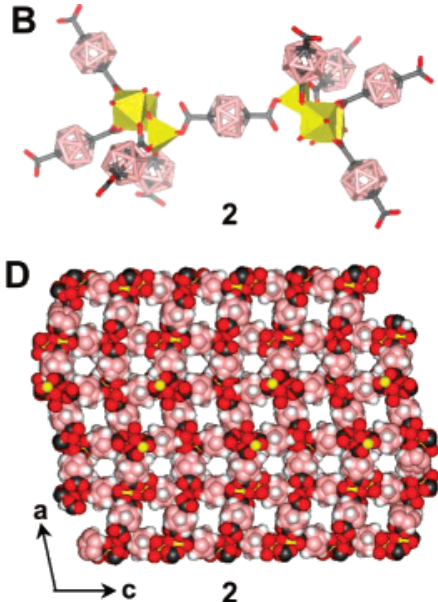

Figure 1. Crystallographically derived (a) structure of 1, (b) topology and connectivity of 2, (c) 3-D topology and connectivity of 2, (d) space-filling packing diagrams of $\mathbf{2}$ down $b$ axes with DEF removed from $\mathrm{Zn}_{3} \mathrm{OH}$ clusters. The coordinated DEF molecules are omitted for clarity $(b-d)$.
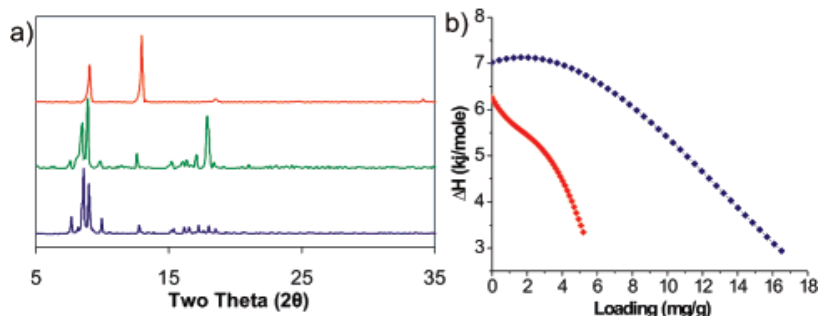

Figure 2. (a) PXRD patterns: simulated pattern based on the single-crystal structure of $\mathbf{2}$ (bottom), $\mathbf{2}$ as synthesized (middle), and $\mathbf{4}$ (top); (b) heats of adsorption $\left(\Delta H_{\text {ads }}\right)$ for $\mathrm{H}_{2}$ in $\mathbf{4}$ (blue) and $\mathbf{3}$ (red).

in an octahedral geometry. In addition, one of the dicarboxylate ligands in the structure is ligated to zinc through only one oxygen atom. The zincs are further connected by a triply bridging hydroxide ion. ${ }^{14}$ Thermogravimetric analysis (TGA) of $\mathbf{2}$ revealed mass losses between 125 and $175{ }^{\circ} \mathrm{C}$ and $175-250{ }^{\circ} \mathrm{C}$, assigned to free and coordinated DEF, respectively, but no further mass loss up to 500 ${ }^{\circ} \mathrm{C}$. Elemental analysis measurements of the crystalline material heated under vacuum at $300{ }^{\circ} \mathrm{C}$ confirmed the removal of the coordinated DEF. Powder X-ray diffraction (PXRD) measurements established that although the crystallinity is retained, the structure is irreversibly altered. We have not yet been able to obtain a singlecrystal structure of the DEF-free version of the MOF (4) (Figure 2a). Infrared data are inconclusive regarding whether the partially coordinated carboxylate of $\mathbf{2}$ becomes fully coordinated in $\mathbf{4}$ (Supporting Information, Figure S9). Nonetheless, the number of coordination sites occupied by DEF in $\mathbf{2}$ is greater than the number 


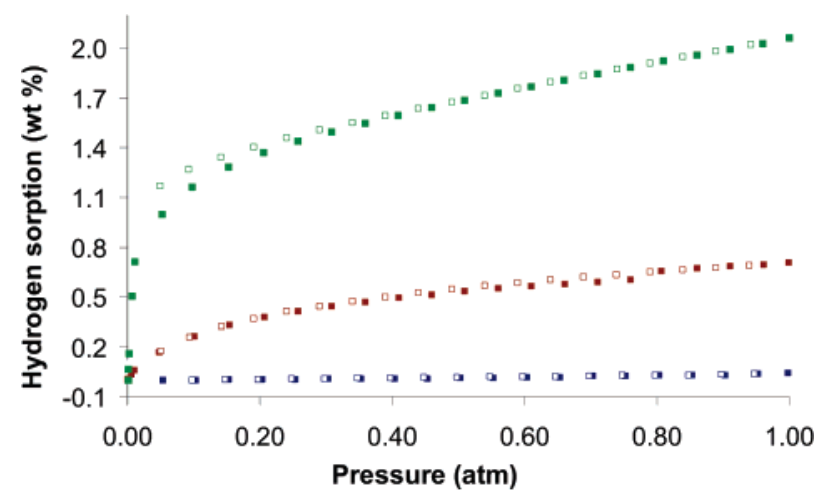

Figure 3. Adsorption (solid squares) and desorption (empty squares) isotherms for $\mathrm{H}_{2}$ uptake by chloroform-treated $\mathbf{2}$ (blue), $\mathbf{3}$ (red), and $\mathbf{4}$ (green) at $77 \mathrm{~K}$.

of coordination sites needed for complete coordination of $p-\mathrm{CDC}^{2-}$. This mismatch may result in coordinatively unsaturated or at least highly reactive metal sites. ${ }^{15}$ Adsorption measurements (Figure S6) were used to determine the $\mathrm{N}_{2}$-accessible surface areas of 3 (compound $\mathbf{2}$ evacuated at $100{ }^{\circ} \mathrm{C}$ ) and 4 . The Brunauer, Emmett, and Teller (BET) surface areas are 248 and $152 \mathrm{~m}^{2} / \mathrm{g}$, respectively. Notably, despite the removal of coordinated DEF, the conversion of $\mathbf{3}$ to $\mathbf{4}$ decreases the size of the most prevalent pores from 6 to $5 \AA$ (Figure S10).

In contrast to modest $\mathrm{N}_{2}$ adsorption, $\mathbf{4}$ displays remarkably high $\mathrm{H}_{2}$ uptake at $77 \mathrm{~K}: 2.1 \%\left(25 \mathrm{mg}\right.$ of $\mathrm{H}_{2} / \mathrm{cm}^{3}$ of 4$)$ at $1 \mathrm{~atm}$. This is apparently triple the uptake of $\mathbf{3}$ (volumetric measurements; Figure 3 ) and stands in striking contrast to unheated samples of 2 (i.e., no uptake even after one week of exposure to chloroform (often effective for solvent exchange) and ambient vacuum). Further comparison of $\mathbf{3}$ and $\mathbf{4}$ reveals that at 1 atm the latter takes up about 6 additional $\mathrm{H}_{2}$ molecules per $\left[\mathrm{Zn}_{3}(\mathrm{OH})\right]^{+5}$ cluster. It is tempting to attribute the enhanced uptake to putative open metal sites, although the observed reduction of pore size might also account for the findings. ${ }^{16}$ The $\mathrm{H}_{2}$ results for $\mathbf{4}$ compare favorably to those for a variety of other MOFs measured under the same conditions and indeed are exceeded by only three other framework materials, ${ }^{7 \mathrm{a}-\mathrm{c}}$ the highest being $2.45 \% .{ }^{7 \mathrm{a}}$

Isosteric heats of adsorption for $\mathrm{H}_{2}$ in $\mathbf{3}$ and $\mathbf{4}$ were obtained by fitting 77 and $87 \mathrm{~K}$ isotherms to appropriate virial equations (Figure 2b). ${ }^{17}$ The $\Delta H_{\text {ads }}\left(\mathrm{H}_{2}\right)$ values for $\mathbf{4}$ are substantially higher than for 3 over the entire loading range. These results are likewise qualitatively consistent with effects expected from reduction of pore size and/or formation of open metal-coordination sites. To summarize, the first carborane-based MOF (2) has been synthesized. Removal of the coordinated solvent molecules triples the uptake of $\mathrm{H}_{2}$ by the material at $77 \mathrm{~K}$ and 1 atm ( 4 vs 3 ) despite a decrease in surface area and reduction of $\mathrm{N}_{2}$-accessible pore volume. The resistance to pore collapse upon conversion of $\mathbf{3}$ to $\mathbf{4}$ likely reflects the rigidity of the dicarborane, its 3-dimensional sterics, and its inability to benefit greatly from stacking-type (collapsed structure) van der Waals interactions. Work on related carborane-based MOFs and on chemical separations using $\mathbf{4}$ is in progress.
Acknowledgment. J.T.H. gratefully acknowledges the Office of Science, U.S. Dept. of Energy (Grant No. DE-FG02-01ER15244), Argonne Natl. Lab (Fellowship for K.L.M.) and the NU NSF-NSEC for financial support. C.A.M. acknowledges the ARO, AFOSR, and NIH (Director's Pioneer Award). M.F.H. acknowledges support from the NSF.

Supporting Information Available: Experimental procedures for the synthesis of $p-\mathrm{CDCH}_{2}, 2$ and 4; X-ray crystallographic files for $p$ - $\mathrm{CDCH}_{2}$ and $\mathbf{2}$ in CIF format; TGA, FTIR, $\mathrm{N}_{2}$ isotherms and heat of adsorption plots of $\mathbf{2}$ and $\mathbf{4}$. This material is available free of charge via the Internet at http://pubs.acs.org.

\section{References}

(1) Oh, M.; Mirkin, C. A. Nature 2005, 438, 651-654.

(2) Min, K. S.; Suh, M. P. J. Am. Chem. Soc. 2000, 122, 6834-6840.

(3) (a) Cho, S. -H.; Ma, B.-Q.; Nguyen, S. T.; Hupp, J. T.; Albrecht-Schmitt, T. E. Chem. Commun. 2006, 2563-2565. (b) Wu, C. D.; Hu, A.; Zhang, L.; Lin, W. J. Am. Chem. Soc. 2005, 127, 8940-8941. (c) Gomez-Lor, B.; Gutierrez-Puebla, E.; Iglesias, M.; Monge, M. A.; Ruiz-Valero, C.; Snejko, N. Chem. Mater. 2005, 17, 2568-2573. (d) Kitaura, R.; Onoyama, G.; Sakamoto, H.; Matsuda, R.; Noro, S. I.; Kitagawa, S. Angew. Chem. Int. Ed. 2004, 43, 2684-2687.

(4) Evans, O. R.; Lin, W. Chem. Mater. 2001, 13, 2705-2712

(5) (a) Lee, E. Y.; Jang, S. Y.; Suh, M. P. J. Am. Chem. Soc. 2005, 127, 6374-6381. (b) Dinca, M.; Long, J. R. J. Am. Chem. Soc. 2005, 127 9376-9377.

(6) Zhao, B.; Chen, X. Y.; Cheng, P.; Liao, D. Z.; Yan, S. P.; Jiang, Z. H. J. Am. Chem. Soc. 2004, 126, 15394-15395.

(7) (a) Liu, Y.; Eubank, J. F.; Cairns, A. J.; Eckert, J.; Kravtsov, V. C.; Luebke, R.; Eddaoudi, M. Angew. Chem., Int. Ed. 2007, 46, 3278-3283. (b) Chen, B.; Ockwig, N. W.; Millard, A. R.; Contreras, D. S.; Yaghi, O. M. Angew. Chem., Int. Ed. 2005, 44, 4745-4749. (c) Dinca, M.; Dailly, A.; Liu, Y; Brown, C. M.; Neumann, D. A.; Long, J. R. J. Am. Chem. Soc. 2006 128, 16876-16883. (d) Choi, H. J.; Suh, M. P. J. Am. Chem. Soc. 2004 126, 15844-15851. (e) Bradshaw, D.; Claridge, J. B.; Cussen, E. J.; Prior T. J.; Rosseinsky, M. J. Acc. Chem. Res. 2005, 38, 273-282. (f) Kitagawa, S.; Kitaura, R.; Noro S. Angew. Chem., Int. Ed. 2004, 43, 2334-2375. (g) Latroche, M.; Surblé, S.; Serre, C.; Mellot-Draznieks, C.; Llewellyn, P. L.; Lee, H.; Chang, J.; Jhung, S. H.; Férey, G. Angew. Chem., Int. Ed. 2006, 45, 8227-8231. (h) Mulfort, K. L.; Hupp, J. T. J. Am. Chem. Soc 2007, 129, 9604-9605.

(8) However, the use of phenyl boronic acids as building blocks for high porosity, metal-free, covalent organic frameworks has recently been reported, see: El-Kaderi, H. M.; Hunt, J. R.; Mendoza- Cortés J. L.; Côté, A. P.; Tylor, R. E.; O’Keeffe, M.; Yaghi, O. M. Science 2007, 316, 268272.

(9) Hawthorne, M. F. Advances in Boron Chemistry; Special Publication No. 201; Royal Society of Chemistry: London, 1997; Vol. 82, p 261.

(10) (a) Hawthorne, M. F.; Farha, O. K.; Julius, R.; Ma, L.; Jalisatgi, S. S.; Li, T.; Bayer, M. J. ACS Symp. Ser. 2006, 917, 312-324. (b) Julius, R. L. Farha, O. K.; Chiang, J.; Perry, L. J.; Hawthorne, M. F. Proc. Natl. Acad. Sci. U.S.A. 2007, 104, 4808-4813.

(11) Panella, B.; Hirscher, M. Adv. Mater. 2005, 17, 538-541.

(12) Pan, L.; Parker, B.; Huang, X.; Olson, D. H.; Lee, J. Y.; Li, J. J. Am Chem. Soc. 2006, 128, 4180-4181.

(13) (a) Hausdorf, S.; Baitalow, F.; Seidel, J.; Mertens, F. J. Phys. Chem. A 2007, 111, 4259-4266. (b) Liao, J. H.; Lee, T. J.; Su, C. T. Inorg. Chem. Commun. 2006, 9, 201-204. (c) Loiseau, T.; Muguerra, H.; Ferey, G.; Haouas, M.; Taulelle, F. J. Solid State Chem. 2005, 178, 621-628.

(14) For another example of such bonding, see: Vodak, D. T.; Braun, M. E.; Kim, J.; Eddaoudi, M.; Yaghi, O. M. Chem. Commun. 2001, 2534-2535.

(15) See for example: Moon, H. R.; Kobayashi, K.; Suh, M. P. Inorg. Chem. 2006, $45,8672-8676$

(16) Jhung, S. H.; Kim, H. K.; Yoon, J. W.; Chang, J. S. J. Phys. Chem. B 2006, 110, 9371-9374.

(17) Czepirski, L.; Jagiello, J. Chem. Eng. Sci. 1989, 44, 797-801.
JA076167A 